ANUARIO DE ESTUdIOS MEDIEVALES 49/2, julio-diciembre de 2019, pp. 589-617

ISSN 0066-5061

https://doi.org/10.3989/aem.2019.49.2.08

\title{
LAS RELACIONES ENTRE LAS VIUDAS URBANAS Y EL CABILDO DE PAMPLONA EN EL SIGLO XIV
}

\author{
THE RELATIONS BETWEEN URBAN WIDOWS AND \\ THE CATHEDRAL CHAPTER IN THE $14^{\text {th }}$ CENTURY
}

\author{
ÁNGELES GARCÍA DE LA BORBOLLA \\ Universidad de Navarra \\ https://orcid.org/0000-0002-3634-7255
}

\begin{abstract}
Resumen: En este estudio se trata de analizar la dimensión social del cabildo de la catedral de Pamplona, es decir su proyección urbana más allá del espacio que conforma el conjunto catedralicio. Para ello, se estudiarán las relaciones creadas y mantenidas con un grupo de mujeres vecinas de la ciudad de Pamplona en el siglo XIV, algunas de las cuales a priori viven una situación más desfavorecida, como son las viudas. Así veremos cómo se establecen nexos de unión entre ambos grupos, especialmente a través de las donaciones de bienes materiales, que tienen una clara finalidad espiritual.
\end{abstract}

Palabras clave: cabildo; viudas; catedral de Pamplona; siglo XIV.

Abstract: This article aims to analyse the social function of the cathedral chapter of Pamplona and its urban projection. It will focus on the specific relationship created and maintained with widows, one of the disadvantaged groups in fourteenth-century society. It will illustrate how links were established between the two groups, especially through donations of material goods that have a clear spiritual purpose.

Keywords: cathedral chapter; widows; cathedral of Pamplona; $14^{\text {th }}$ century.

\section{SUMARIO}

1. Introducción.-2. En los primeros tiempos de la catedral.-3. Las viudas y el cabildo en el siglo XIV.- 4. Consideraciones finales.- 5. Bibliografía citada.

\section{INTRODUCCIÓN}

La definición más clara y sencilla del cabildo puede ser el clero catedralicio. Se trata de un grupo de hombres, canónigos regulares, que en el caso pamplonés no es muy numeroso, no llegando a superar la treintena a lo largo del periodo estudiado ${ }^{2}$. Además, en la catedral de Pamplona su número no fue

${ }^{1}$ Abreviaturas utilizadas: $\mathrm{ACP}=$ Archivo de la Catedral de Pamplona; $\mathrm{CCP}=$ Catálogo de la Catedral de Pamplona (Goñi Gaztambide 1965); ColCP = Colección Diplomática de la Catedral de Pamplona (Goñi Gaztambide 1997).

2 Jiménez 1992, pp. 391-408.

Citation / Cómo citar este artículo: García de la Borbolla, Ángeles (2019), Las relaciones entre el cabildo de Pamplona y una parte del tejido social urbano en el siglo XIV: las viudas, "Anuario de Estudios Medievales" 49/2, pp. 589-617. https://doi.org/10.3989/aem.2019.49.2.08

Copyright: (C) 2019 CSIC. Este es un artículo de acceso abierto distribuido bajo los términos de la licencia de uso y distribución Creative Commons Reconocimiento 4.0 Internacional (CC BY 4.0). 
nunca fijo, más bien dependía de las rentas que en cada momento se percibían, y a diferencia de otros cabildos hispanos que empezaron a secularizarse entre los siglos XIII y XIV, la vida en común va a prolongarse en Pamplona hasta el siglo XIX. En su seno destaca la figura del prior, la dignidad más importante, cuyas atribuciones eran velar por el cumplimiento de las normas y estatutos, sustituir al obispo en su ausencia, presidir las reuniones del cabildo y juzgar las causas y conflictos entre los capitulares. Junto a él, encontramos otra serie de dignidades o canónigos que representan el sector más selecto y preeminente del mismo y que debían estar ordenados con las tres órdenes mayores (presbítero, diácono y subdiácono) ${ }^{3}$.

Sin embargo, no cabe imaginar un grupo de hombres de vocación religiosa aislados del contexto urbano donde se desarrolla día tras día su vida. Sin lugar a dudas, su primera función y por ende la más importante era mantener la vida religiosa, el culto, la liturgia del que era el templo por excelencia de la ciudad: la catedral. Pero también a través del estudio de la documentación conservada en los fondos catedralicios vemos a estos individuos integrantes del cabildo, actuando como agentes económicos que gestionan sus bienes patrimoniales y que, por lo tanto, con sus compra-ventas o arriendos, contribuyen a desarrollar una importante dinámica en la vida económica de la ciudad. Por ejemplo, en el caso navarro, esto es especialmente significativo en el siglo XIV a raíz de la cesión del dominio temporal de la ciudad por parte del obispo y el cabildo a los reyes y con la consiguiente compensación económica que se recibe a comienzos de siglo ${ }^{4}$; o bien, en las últimas décadas de ese mismo siglo, otro exponente claro de su dinamismo económico y social es su papel en la repoblación del burgo de la Navarrería, el núcleo de población original constituido alrededor de la catedral ${ }^{5}$. A consecuencia de la terrible contienda

\footnotetext{
${ }^{3}$ En el caso del cabildo de Pamplona encontramos las dignidades de oficios: Prior, subprior, arcediano de la cámara, arcediano de la tabla, chantre, hospitalero, enfermero y tesorero. Y dignidades territoriales como el arcediano de la Valdonsella, arcediano de Valdeaibar, arcediano de Eguiarte, arcediano de santa Gema, arcediano de san Pedro de Usún, arcediano de Eguiarte y prior de Velate.

${ }^{4}$ Fortún 1994, p. 83. En 1319 la catedral cedió al monarca todo el señorío de Pamplona, los castillos de Salinas de Oro y Monjardín y demás bienes disputados a cambio de rentas en metálicos de 500 libras, una cifra que triplicaba holgadamente los rendimientos calculados de los bienes cedidos por la iglesia. Además, incluía el compromiso del monarca para autorizar la repoblación de los Burgos de la Navarrería y San Miguel destruidos en la guerra de 1276. Las rentas del cabildo se asignaron sobre las viñas de Pamplona, aunque la mayor parte de las mismas se transfirieron a la iglesia mediante cesión de varias parroquias de patronato regio. El proceso no fue tan sencillo y rápido porque el clero desconfió hasta que recibió las viñas en 1321.

${ }^{5}$ García de la Borbolla 2013,pp. 157-175; 2016, pp. 255-273. El patrimonio del cabildo de la catedral de Pamplona logra en la primera mitad del siglo XIV unas sólidas bases gracias no sólo a las generosas entregas de particulares o a las herencias de ricos burgueses o miembros del propio cabildo, sino también a las compras y permutas realizadas por el propio cabildo que van engrandeciendo su patrimonio compuesto fundamentalmente por bienes rústicos y urbanos.
} 
civil desencadenada en 1276 entre los tres barrios de la ciudad, San Nicolás, san Cernín y la Navarrería, ésta quedo literalmente arrasada, exigiendo un cambio urbanístico importante que pasaba por su casi total reedificación ${ }^{6}$.

No obstante, en esta ocasión queremos analizar no tanto la actividad económica del cabildo, sino más bien su papel como agentes sociales en el marco urbano de la ciudad de Pamplona, sin olvidar nunca la condición religiosa de estos capitulares ${ }^{7}$. Se trata de estudiar las relaciones de los miembros de esta institución con el contexto social urbano más próximo, los vecinos de la ciudad de Pamplona. Para este respecto hemos elegido un sector de población concreto: las mujeres y dentro de este amplio grupo de género, hemos fijado especialmente la atención en aquellas mujeres que aparecen como sujetos protagonistas en la documentación. A priori esta individualidad documental puede deberse a varios motivos: en primer lugar, a su estado civil, solteras o viudas; pero también aquellas casadas que por iniciativa propia emprenden una acción económica extraordinaria, como podría entenderse una donación en favor del cabildo. Evidentemente, nuestra elección no resulta caprichosa, sino que ha obedecido a una cantidad significativa de documentos conservados en los fondos del archivo catedralicio que tienen como protagonistas por un lado al cabildo, en su conjunto o un miembro particular del conjunto canonical; y por el otro, a mujeres que viven una determinada condición biográfica, la viudedad, que a su vez comportaba una situación social y económica determinada. El objetivo de este estudio es poner de manifiesto su presencia real en un determinado contexto, integrándolas, haciéndolas visibles, en un ámbito donde sabemos que estuvieron. En definitiva, presentándolas como protagonistas junto a los varones en el devenir social, mostrando su intervención en todos aquellos asuntos en los que sabemos estuvieron presentes ${ }^{8}$. En este

\footnotetext{
${ }^{6}$ Martinena 1996, p. 143.

${ }^{7}$ Lop 2003, p. 29. Las iniciativas en que se materializaba el contacto del cabildo con los fieles apuntaban tres direcciones básicas: función religiosa, es decir garantizar a los fieles los servicios y celebraciones propias de la fe que profesaban (misas, procesiones, aniversario, rezos horas, y todos actos litúrgicos); función cultural y educativa, al mantener escuelas catedralicias son punto de referencia en la vida intelectual de su tiempo; función benéfico-asistencial con la que paliar parte de la miseria y marginación de la población urbana (hospitales, limosnas, niños expósitos...).

${ }^{8}$ Val Valdilvieso 2004, p. 29. Hemos de señalar que el objetivo de nuestro trabajo es mostrar la proyección social del cabildo de la catedral de Pamplona en la Baja Edad Media. No obstante, es cierto que esta contribución puede incluirse entre las muchas destinadas a engrosar la historia de las mujeres en la Edad Media peninsular iniciada en la década de los años 70 del siglo pasado y que contó con el impulso de ilustres medievalistas como Cristina Segura. Enumerar trabajos y autores dedicados a esta línea de trabajo sólo en el marco del medievalismo hispano correspondería a un estudio de síntesis historiográfica, como el realizado por la profesora Val Valdivieso. Tan sólo señalaremos algunos títulos más significativos y que han sido consultados: Rojo 1987; García Herrero 1990; García Rubio 2000; Pérez González 2005. En los últi-
} 
sentido, en una primera parte del trabajo haremos un recorrido histórico de la institución canonial y sus relaciones más significativas con esta parte del sector femenino de la población navarra, las viudas. Y a continuación, la segunda parte de nuestro trabajo se centrará en analizar con más detalle esta aportación a la construcción social que tiene como base las relaciones establecidas entre ese grupo de viudas, que además ocupan un nuevo lugar en su propia familia, y una de las instituciones religiosas más importantes en la ciudad de Pamplona en el siglo XIV: el cabildo de la catedral.

\section{EN LOS PRIMEROS TIEMPOS DE LA CATEDRAL}

Desde los primeros tiempos de vida de la catedral románica y del clero que integra la comunidad canonical, emergen entre la documentación mujeres que por iniciativa propia hacen entrega de bienes en favor de la iglesia de Santa María de Pamplona. Estas donaciones materiales tienen como fin beneficios espirituales y son considerablemente frecuentes en el siglo XII. Podríamos hablar de una suerte de "transacción" acorde con la espiritualidad de la época, imbuida en una firme creencia en la vida eterna, en la salvación y en la condenación eterna9. Este valor de las limosnas o donaciones como sufragios ante Dios que borran los pecados del alma queda perfectamente expresado en un documento fechado en 1094. Su protagonista, la condesa Tecla, hija de Diego Alvaroiz, viuda de don Lope conde de Álava y Vizcaya, dona a santa María de Pamplona y a su obispo Pedro toda su hacienda de Villafranca con sus collazos y pertenencias en sufragio de su alma y la de su marido ${ }^{10}$ : verba Domini sunt dicentis: "Date et dabitur uobis"........ait: "Date helemosinam et monia munda sunt uobis, sicut (aqua extinguer ignem) ita helemosina extinguit peccatum".

Hemos de señalar que el derecho de la época en el territorio navarro no ponía trabas a la mujer como otorgante de escrituras públicas y los ejemplos son innumerables. Basta repasar los cartularios de los importantes monasterios de la zona para comprobar como la mujer con una regular periocidad va apareciendo otorgando compraventas, donaciones, ventas, censos...bien por su sola persona (en bienes muebles o inmuebles de su peculio y hacien-

mos años han aparecido trabajos compilatorios de gran interés como el editado por Solorzano, Arizaga, Andrade 2013; o el coordinado por García Herrero, Pérez Galán 2014.

${ }^{9}$ El tema de las actitudes ante la muerte en la Navarra medieval ha sido estudiado hace unos años por las medievalistas Julia Pavón y Ángeles García de la Borbolla, (Pavón, García de la Borbolla 2007).

${ }^{10}$ ColCP, doc. 55; Goñi 1979, p. 267. 
da), con sus hijos, en compañía de su marido ${ }^{11}$. Por otro lado, este documento como muchos otros que se emiten en estas centurias, viene a confirmar a la seo pamplonesa como la principal iglesia de la diócesis, y su incipiente grupo de canónigos se posicionaban como intercesores y receptores de generosas donaciones por parte de los fieles, papel que hasta ahora ejercía casi de modo exclusivo las grandes comunidades monásticas, sobre todo en el caso navarro el monasterio de Leyre. Tal y como expresa José Goñi:

el nuevo género de vida introducido en la iglesia madre de la diócesis, con el consiguiente esplendor del culto litúrgico y la iniciación de una grandiosa catedral, produjeron un fuerte impacto, que se tradujo en una lluvia de privilegios y donaciones a santa María de Pamplona, a su obispo Pedro y a los canónigos, que se fue intensificando en el transcurso del siglo XII ${ }^{12}$.

Unas donaciones patrimoniales que provenían de los estratos más diversos de la sociedad, desde los monarcas, los nobles y caballeros, hasta los ciudadanos de fortunas más modestas. Por otro lado, todos estos documentos reflejan un momento de esplendor que vive la iglesia catedralicia bajo el obispado de Pedro de Roda (1083-1115) donde la autoridad episcopal salió firmemente reforzada, y donde el patrimonio de la sede episcopal y del cabildo aumentó considerablemente. Un esplendor que además tendrá una visible evidencia material: los inicios de las obras de la catedral románica hacia $1100^{13}$.

Como hemos señalado anteriormente en este estudio focalizaremos el tema en muchas mujeres que parecen ser las supervivientes de sus familias, mujeres solas, o mejor dicho mujeres enviudadas, como Sancha de Solchaga, que en su carta de donación a la iglesia de Pamplona de todos los bienes que tiene y pueda tener hasta el momento de su muerte, recuerda la intención de tal acto: pro remissione omnium peccatorum meorum et mariti mei et parentum meorum ${ }^{14}$. O Sancha Acenariz: pro anima mea et pro remissione peccatorum meorum et pro anima domini Acenarii Eneconis et pro animabus que ibi iacent, que sunt meas comendatas, per infinita secula ${ }^{15}$.

${ }^{11}$ Díez de Salazar 1990, p. 98.

${ }^{12}$ Goñi 1979, p. 262. Desde la década de los 20 del siglo XII hasta mediados de esa centuria, en tiempos del obispo Sancho, es un periodo especialmente abundante en donaciones patrimoniales femeninas a la catedral.

${ }^{13}$ Goñi 1979, pp. 269-272.

${ }^{14}$ ColCP doc. 63 (año 1096). Goñi 1979, p. 268.

${ }^{15}$ ColCP, doc. 79 (año 1110). Otros documentos similares, cuyos protagonistas son exclusivamente mujeres y con dataciones parecidas son los siguientes: doc. 83 (año 1110); doc. 104 (año 1104); doc. 128 (año 1116-1121); doc.166 (año 1128); doc. 173 (año 1129); doc. 174 (año 1129). 
La situación de cierto desamparo en que vivían estas mujeres que no contaban con la presencia de su marido, les obligaba a asumir de manera inmediata ciertas responsabilidades en el orden familiar, económico y material, de las que estaban eludidas frecuentemente con anterioridad. Pero también resulta llamativo comprobar en este tipo de documentación una nueva responsabilidad adquirida en otro orden alejado de lo estrictamente material: la intercesión por las almas difuntas próximas. En primer lugar, el marido ${ }^{16}$, en segundo término los parientes, entre los cuales en muchas ocasiones sacan figuras del anonimato que esconde la expresión genérica parentorum meorum. Padres, tías, hermanos e hijos fallecidos: ego domina Auria Semenoiz facio cartam donationis Deo et beate Marie Virgini pro anima de patre meo Semeno Açenaris et pro anima de seniore meo Enecho Ueliz et pro anima de mea thia Andregoto Sanoiz et de mea germana Tota Semeoniz ${ }^{17}$. Son muchos los ejemplos de esta actitud de recuerdo hacia las almas de los fallecidos con anterioridad y vinculados por la sangre con la protagonista del documento. Es el caso de María de Iza que dona un prado que antes pertenecía a su padre y que ahora era de su entera propiedad, al obispo y al cabildo. Termina el documento considerando que este gesto se aplicará a la redención de sus pecados, y por las almas de su padre, hermanos y otros parientes: pro redemptione pecatorum meorum et pro animabus patris et fratris mei et aliorum parentum meorum ${ }^{18}$. Por otro lado, en muchos casos las viudas, como nuevas administradoras y usufructuarias de los bienes familiares, son continuadoras de la labor de sus maridos, incluso en este tema tan concreto como las donaciones piadosas. Esa individualización de la mujer a la muerte de su marido es aún más evidente en los testamentos ${ }^{19}$. De este modo encontramos el matrimonio formado por García Sanz de Ayerza y Toda Bertrandez que entre 1141-1142 hacen dos cartas de donación de todas sus haciendas en Oyerza, y del palacio de Arlegui, lugar donde su hijo es capellán, a Santa María de Pamplona.

${ }^{16}$ ColCP, doc. 438: "Ego domina Santia Berderadiz de Çariquiegui dono Deo et Sancte Marie de Pampilona partem honoris mei quam habeo in Çalba propter anima uiri mei".

${ }^{17}$ ColCP, doc. 175. También en doc. 231: "Ego domina Leundia de Gorrauz, cum consilio et uoluntate filie domine Aurie mee et generis mei senioris Eneco Ortiz et domine Andregote, priuigne mee, pro anima mea et uiri mei senioris Acenarii Semenonis et filiorum meorum". En esta ocasión la donación pretende conseguir de los canónigos una sepultura para ella, su marido e hijos en el claustro de la catedral.

${ }^{18} \mathrm{ColCP}$, doc. 400 (año 1192). Muchas de estas mujeres experimentaron incluso una doble viudedad como es el caso de María de Lehet. En doc. 255 (año 1147): "hoc autem facio auctoritate et spontanea uoluntate filiorum meorum Petri uidelicet et Martini pro remissione peccatorum meorum et pro animabus uirorum meorum senioris uidelicet Eneco Lopeyz de Soria, qui moriens eas michi dimisit, et senioris Lupi Eneconis de Borouia, qui eas post mortem illius multum amplificauit et meliorauit".

${ }^{19}$ Rojo 1987, p. 126. 
La finalidad de esta donación es clara: ut habeamus partem in societate et in fraternitate canonicorum pampilonensium mensium. Es una donación post mortem, así que mientras ambos vivan, se comprometen a pagar un censo de diez sueldos anuales a la catedral por la festividad de San Martín. Años más tarde, en concreto casi cuarenta, en 1180 encontramos otra carta de donación del mismo matrimonio dejando dos collazos en Arlegui con sus respectivos censos, por sufragio de sus almas y las de sus parientes difuntos. Sin embargo, en esta ocasión al final del documento, interviene de manera singular la esposa, lo que nos lleva a pensar que su marido ha fallecido: Ego Tota Bertrandez concedo et confirmo sicut mandauit maritus meus Garsias Sanciusin uita sua, sic concedo et confirmo supra scriptum donatiuum post mortem suam cum meo palatio ${ }^{20}$.

Como hemos visto hasta ahora y las donaciones se hacían generalmente al obispo y al conjunto del cabildo. Además, aunque muchas de ellas no instituían una fundación piadosa post mortem, como un aniversario o una capellanía, si presuponían la oración de ese clero por la salvación de determinadas almas. Sin embargo, en algunos ejemplos, las donantes especifican de manera más precisa el destino de sus bienes. En estos casos, las donaciones van dirigidas a ayudar a la vida de los canónigos, ya fuera en el orden material, mejorando sus condiciones de vida, o bien apoyando su labor asistencial. En el caso de la catedral de Pamplona, esta última tarea se realizaba en el hospital de San Miguel, abierto a pobres, peregrinos o enfermos ${ }^{21}$. La carta de donación de Aurea Semeoniz fechada en 1129 es un ejemplo de ello, pues deja una tercera parte de sus bienes a la labor asistencial de ese hospital: post obitum meum, hoc quod inventum ibi fuerit de mobile, de pane, et vino et de bestias et de toto auere, remaneant duas partes ad Sancta Maria de Pampilona et terciam partem ad illo hospitale de Pampilona ${ }^{22}$.

Otro servicio dentro de la vida canonical que resultaba de singular importancia era la enfermería. Un complejo situado en el recinto catedralicio y destinado a cuidar de los canónigos enfermos y ancianos. Encontramos donantes que conociendo la necesidad de mantener este servicio dejan bienes al enfermero, canónigo al frente de esta dependencia ${ }^{23}$. Es el caso de la viuda María Mondela quien dona una collaza y un palacio en Sansoain. Al mismo

${ }^{20}$ ColCP, doc. 361. CCP. 219, 221, 341 .

${ }^{21}$ El primer documento fundacional de este hospital está fechado hacia 1125. En él un tal Miguel, agradecido por los beneficios recibidos desde su infancia por la catedral, dona unas casas junto a la puerta de la catedral, estas viviendas y todas sus pertenencias se transformarán pronto en un hospital para pobres y peregrinos. CCP. 139.

${ }^{22}$ ColCP, doc. 175.

${ }^{23}$ Gámez 1998, pp.745-762. 
tiempo que manda que tanto en vida suya como tras su muerte, se entregue a la enfermería varias medidas de cereal:

certam peitam scilicet singulis annis unum kaficium de tritico et unum kaficium de auena et unum peditem ad laborem per quatuor dies in anno, quo tempore infirmario pampilonensi placuit et ipsis donantibus istam peitam non grauet eos infirmarius in maiori peita neque in maiori censu ${ }^{24}$.

Muy significativo es el documento fechado en 1223 que tiene como protagonista a María Ortiz, viuda del carnicero Domingo Ezquer. Esta mujer, conociendo el frío que pasaban los canónigos en invierno mientras comían, dona una casa en la población de San Nicolás a García de Aoiz, un pariente suyo, a condición de que este pague al cabildo 40 sueldos para leña con la que se calienten los canónigos en el refectorio ${ }^{25}$. Una lectura similar tiene la donación de numerosos bienes que realiza Sanza Fortiz. En la larga lista encontramos desde cálices y dalmáticas, frontales de altar, paños, vasos de plata y alhajas, todos ellos destinados al culto divino de la catedral ${ }^{26}$. O Sancha de Orella quien dona en 1183 un collazo en Paternain, en esta ocasión para ayudar al sostenimiento de la luminaria del templo: ut sit in perpetuum ad seruicium luminarie ipsius ecclesie ${ }^{27}$.

Por último, y no menos importante se encuentran algunos ejemplos de donaciones personales, más frecuentes en los siglos plenomedievales que en los posteriores. Es decir la persona, en este caso mujeres de las que no sabemos su estado civil, pero podemos pensar que quizás alguna había enviudado, se entregan junto con sus bienes, y son acogidas por la comunidad canonical que debe velar por su sustento material y espiritual: ego domina Oria similiter do memetipsam et omnia que habeo uel habere possum Deo et beate genitrici eius Marie et sacro conuentu in ecclesie Pampilonensis ${ }^{28}$. En este tipo de actuación, entendida siempre en el marco espiritual, pues se trata de una entrega

${ }^{24}$ ColCP, doc. 523 (año 1220).

${ }^{25}$ ColCP, doc. 546.

${ }^{26} \mathrm{ColCP}$, doc. 451.

${ }^{27} \mathrm{ColCP}$, doc. 370 .

${ }^{28}$ ColCP, doc. 449 (siglo XII). Esta práctica no era exclusiva del género femenino como demuestran los siguientes ejemplos. En 1140, Ayoro Ortiz se dona a sí mismo con la condición de que durante su vida los canónigos le den alimento y vestidos. CCP. 214. Otros ejemplos ponen como condición poder ser admitido como canónigo si el donante alguna vez lo deseaba. Tal es el caso de García Alcalá en su carta de donación fechada en 1142 y donde además pide sepultarse en el claustro de la catedral. (CCP. 222). O de Enneco Fortuniones de Zabaldica quien en 1152 pide ser admitido él y su hijo como canónigos (CCP. 257); el senior Lope Lopeiz de Zurien se dona así mismo para ser canónigo (CCP. 276); por último, el senior Acenar Oriol 1167-1168. (CCP. 296). 
física para dedicarse a una vida de oración, el cabildo asume un nuevo rol. La comunidad canonical receptora se convierte también en protectora, en garante de la vida material de esas mujeres que han decidido "abandonar su vida y sus bienes" para dedicarse a una vida de oración y penitencia. Así por ejemplo, Sancha López dona a la catedral todos sus bienes pero advierte al final del documento que si ella por expiar sus pecados decidiera empobrecerse, el obispo y el cabildo la sostengan y administren sus bienes rectamente: verumptamen si forte, peccatis exigentibus, decidero in aliquam paupertatem quod ego non ualeam illud bene rege, episcopus et canonici sustentent me et audiuuent illud regere $^{29}$.

En este contexto resulta de gran interés el siguiente documento fechado el 21 de junio 1283, en el que el prior y el cabildo se comprometen a entregar anualmente a María Ederra y a su criada, paniaguadas de la catedral, ciertas cantidades de trigo, vino y dinero para indumentaria:

singulis duodecim kaficia tritici, mensure pampilonensi, et octo conquas del bono musto puro, et quatuor coquas del primo maliolo quod uulgariter primera agoa dicti, mesura pampilone, et sexaginta solidos sanchorum ad coquina, et octuaginta solidos sanchorum ad opus indumentorum suorum volentes ${ }^{30}$.

Con todo ello ambas mujeres mantendrían unas buenas condiciones de vida, después de haber entregado tanto sus personas como sus bienes a la institución eclesiástica en un acto de donación formal (considerantes beneplacita et obsequia utilia multa libere ac fideliter nobis). Se trata sin duda de mujeres, paniaguadas, que voluntariamente deciden llevar una vida de mayor experiencia religiosa, de manera que renunciando "al mundo" se entregan a una vida de oración, viviendo bajo el amparo de una comunidad eclesiástica en cuanto a sus necesidades materiales básicas. En este caso es el cabildo de la catedral de Pamplona, la institución que las ampara tanto en su subsistencia material como también espiritualmente.

Terminamos este periodo con el testamento de una mujer, de la que tampoco tenemos datos para saber si era soltera o viuda, aunque lo cierto es que no encontramos ninguna referencia a su "posible" marido, ni a "posibles" hijos. Se trata de un ejemplo interesante pues las mandas piadosas recogidas en sus últimas voluntades nos llevan a pensar en cierta relación y afinidad espiritual de la testadora con el clero catedralicio. Ella es Milia Beunza una mujer de sólida posición económica, probablemente rica burguesa,

${ }^{29}$ ColCP, doc. 156 (año 1126).

${ }^{30}$ ACP Cámara, 35. 
situación deducida de los numerosos bienes que reparte (sobretodo viñas, casales y huertos). Además, los beneficiarios de su testamento, hermano y sobrinos, son mercaderes de Pamplona. Entre sus últimas voluntades redactadas en 1285 funda una capellanía en la catedral de Pamplona, y quien debe velar de su mantenimiento es su sobrino Domingo, un mercader. Para ello deja un huerto y una viña que poseía en el término de Aranzadi, de estos bienes debe sacar la cantidad de 20 sueldos anuales que entregará al cabildo, en particular a la pitancería, quien a su vez debe poner un capellán que celebre su aniversario: lo dit conuent que meta un capelan qui cantia missa por totz temps per la mia anima. A esta fundación que el cabildo aprueba en 1294, le siguen otras mandas piadosas como veinte sueldos para la fábrica de la catedral; alas dones del hospital de San Miguel XX sueldos para pitanca, y XXX soltz para la tabla dels calonges ${ }^{31}$. A nuestro juicio este tipo de documento, los testamentos o sin presentar ese formato protocolario, las fundaciones piadosas (capellanías y aniversarios), resultan especialmente interesantes ya que puede arrojar luces sobre las relaciones creadas y mantenidas en el tiempo, entre el clero y los fieles. En particular, en este estudio entre las mujeres viudas y el cabildo de la catedral de Pamplona como analizaremos a continuación.

\section{LAS VIUDAS Y EL CABILDO EN EL SIGLO XIV}

Como hemos visto hasta ahora con los precedentes cronológicos en la vida de la catedral, la mujer y en particular la viuda es un sujeto de estudio mucho más visible. Hemos de admitir que este grupo de mujeres despierta un especial interés, su estado no pasaba desapercibido en la sociedad que las rodea, y para el historiador su suerte, sus posibilidades, su desarrollo vital suscita la curiosidad. Por una parte, la viuda se presenta como un ser débil que debe ser protegido y asistido por la sociedad. Despierta compasión dentro de la espiritualidad cristiana como ya aparecía recogido en textos del Antiguo Testamento (Baruc 6, 37; Isaías 1, 17) o en las cartas paulinas (1 carta a Timoteo). Y por otra parte, la viudedad aparece como el estado en que la mujer se movía con mayor libertad e independencia, solamente la mujer viuda llegaba a ser cabeza de familia.

\footnotetext{
${ }^{31}$ ACP, O 10. En 1294 el cabildo formaliza la fundación de esta capellanía. ACP, O 11. Años más tarde, en 1336, ya fallecida doña Milia Beunza, el cabildo le requiere a Domingo y a su mujer, sobrino nieto de la donante y usufructuario de los bienes donados, que cumpla con la capellanía y los veinte sueldos para pitanza en su aniversario. Finalmente, en 1372 se consigue que esas propiedades se cedan al cabildo para que mantengan la capellanía fundada. ACP, O 9.
} 
En la época medieval, la viudedad femenina tiene un sentido ambivalente e interesado: por un lado, la documentación, en especial la legislativa, denota su situación privilegiada, favoreciéndola frente a otras situaciones femeninas; y por otro, presenta la contrapartida de que la mujer mantenga la necesaria permanencia en ese estado a cambio de disfrutar de tal concesión ${ }^{32}$. Así, por ejemplo, la casada no puede disponer de sus arras ni de su dote, cosa que si le está permitido a la viuda. La dote continúa siendo la base de las garantías económicas de que dispone la mujer en caso de viudedad, aunque son también de la viuda los regalos que el marido le hizo en vida, así como las mandas y donaciones testamentarias del marido muerto ${ }^{33}$. Ésta en caso de no tener ningún hijo con edad suficiente, capacitado para administrarle el patrimonio, debe encargarse de la administración de los bienes de la familia hasta que su hijo alcance la mayoría ${ }^{34}$.

En este sentido resulta ilustrativo aproximarnos someramente a la documentación jurídica que regula esta condición en el panorama del norte peninsular más próximo al reino de Navarra. Así en el fuero de Soria es destacable el esfuerzo por reforzar el apoyo a la familia simple. La intención última es dotar a la viuda de la capacidad jurídica y económica suficiente, como para que esta mujer no se vea obligada a la dependencia de su familia. De este modo, se le reconoce capacidad jurídica para actuar sobre sus bienes, sola o con sus hijos ${ }^{35}$. Por otro lado, en el caso aragonés, la viudedad se entiende desde el siglo XIII como el derecho que tiene el cónyuge viudo al disfrute de los inmuebles privativos del premuerto y de la mitad que a aquel correspondía en los inmuebles consorciales ${ }^{36}$. Mientras que en el derecho catalán aparece una estricta separación de bienes entre el marido y la mujer. La mujer durante su viudedad dependerá legalmente, desde el punto de vista económico de sus propios bienes, lo que ella aporto al matrimonio por medio de la dote u otros bienes parafernales. Unos bienes que en la mayoría de casos no serían suficientes para continuar disfrutando del mismo poder adquisitivo que tenían en vida del marido. Aunque durante el primer año de luto o de llanto la viuda tenía derecho a ser alimentada a cargo del patrimonio del marido ${ }^{37}$.

En el caso navarro, en el matrimonio cada parte conserva los bienes propios de abolengo u otra clase cuando son titulares de ellos antes de casarse; los conseguidos después son gananciales. Esta sociedad de gananciales

\footnotetext{
${ }^{32}$ Rojo 1987, p.172.

${ }_{33}^{33}$ Pérez de Tudela 1984, p. 90.

${ }^{34}$ Segura 1986, p. 126.

${ }^{35}$ Asenjo 1990, p. 55.

${ }^{36}$ García Herrero 1990, p. 321.

${ }^{37}$ Equip Broida 1984, p. 28.
} 
termina con la muerte de uno de los esposos y entra en juego el usufructo viudal. Y en caso de partición de bienes con los herederos del premuerto, los gananciales se reparten por partes iguales entre el supérstite y aquellos ${ }^{38}$. Si el marido muere dejando hijos menores de siete años, los parientes del padre pueden tomar a los hijos y todo lo del padre y criarlos hasta la edad de siete años. A partir de entonces los hijos pueden ir donde quieran tomando la mitad de los bienes del padre y de la madre, menos los vestidos de ella. En caso de que no existiera descendencia los bienes vuelven a su natura, es decir a la $g e$ noylla o parientes más cercanos ${ }^{39}$.

Con esta nueva condición social, con este marco legal, la viuda aparece como un sujeto activo formando parte de la dinámica económica de las ciudades medievales, y ejerciendo sus derechos en la defensa de sus intereses, de su patrimonio y el de su familia. Así evitando en la medida de lo posible caer en situaciones de marginalidad se convierten en auténticos pilares de la estructura familiar ${ }^{40}$. En líneas generales llama la atención la libertad con que estas mujeres parecen actuar, viudas que compran y venden por sí mismas sin problemas, como han puesto de relieve numerosas investigaciones. La participación de la mujer en la economía tanto en el espacio público como privado es un hecho consumado ${ }^{41}$.

El siglo XIV en el reino de Navarra contiene nuevos elementos que definen una nueva coyuntura social. A nivel diocesano, en este siglo acontece uno de los episcopados más brillantes y largos, el de Arnalt de Barbazán (13181355), "pastor de almas y hombre de gobierno, constructor y legislador"42. Además, el siglo XIV fue una centuria especialmente dinámica desde el punto de vista económico para el cabildo de la catedral, donde su nivel patrimonial se ve consolidado tanto por donaciones como por gestiones comerciales de los propios capitulares ${ }^{43}$. Es el siglo donde se terminaron las dependencias canonicales y se inició el actual templo gótico tras el derrumbamiento parcial del románico en $1391^{44}$.

Sin embargo, por otro lado, no podemos desestimar la incidencia de hambrunas en la población del reino en las primeras décadas del siglo XIV. Estas carestías que afectan demográficamente a Navarra son previas a las epi-

${ }^{38}$ Díez 1990, p. 112.

${ }^{39}$ Galán 2004, p. 72.

${ }^{40}$ Carvajal 2004, p. 134.

${ }^{41}$ Val Valdivieso 2004b, p. 114.

${ }^{42}$ La historia de los obispos de Pamplona en el siglo XIV se puede dividir en dos periodos según el origen geográfico de sus prelados: hasta 1356 todos son franceses y después de esta fecha serán de origen Navarro.

${ }^{43}$ García de la Borbolla 2013, 2016.

${ }^{44}$ Goñi 1994,pp. 33-77. 
demias de la segunda mitad del siglo cuya incidencia ha sido objeto de análisis cuantitativo en algunos estudios ${ }^{45}$. Quizás esta sea la razón de ver incrementado significativamente el número de mujeres viudas en la documentación estudiada $^{46}$. Aunque como regla general cabe destacar siempre la mayor cantidad de viudas, comparada con viudos, dado que la mujer se solía casar con un hombre mayor que ella. Pero además el viudo lo era por poco tiempo porque volvía a casarse inmediatamente, mientras que las mujeres a partir de cierta edad permanecían viudas ${ }^{47}$.

Con el dolor de la pérdida acompañándole durante muchos años de su vida y quizás ya la vida entera, la viuda se enfrentaba a un duro papel, la necesidad de mantenerse y de mantener a sus hijos. En el caso navarro, la fórmula económica que le permitía iniciar esta "nueva vida" era el usufructo de fidelidad cuya obligatoriedad se recoge en el Fuero general tal y como ya hemos señalado. En principio no era un derecho universal, pues el Fuero general lo consideraba un derecho exclusivo de infanzones y no villanos. Además, sólo se aplicaba en el caso de tener descendencia ya que en el caso de ausencia de hijos se aplicaba sólo a bienes inmuebles. Esta fórmula situaba a la viuda en una inquilina del patrimonio de su marido, no era una posesión real, no era la dueña de los bienes. Tan sólo era su administradora, lo cual provocó numerosos litigios en el seno de las familias. Aunque no cabe duda que el ser nombradas usufructuarias les permitía sobrevivir. En cierto modo la protegía de la ambición de la familia del esposo difunto. Al mismo tiempo, el usufructo dotaba de mayor autoridad a la madre frente a sus hijos. A partir de ahora adquieren una gran autonomía en la administración del patrimonio familiar sin olvidar que tenían la responsabilidad de seguir manteniendo la estabilidad y la unidad familiar ${ }^{48}$. Por otro lado, si la viuda quería contraer un segundo matrimonio reclamaría su dote y perdía el usufructo de los bienes de su primer marido que pasaban a sus hijos, salvo que una disposición testamentaria se

\footnotetext{
${ }^{45}$ Berthe 1984; Carrasco 1973; Monteano 2002; Castan, Dueñas 2006. Según los estudios realizados en el reino de Navarra parece ser que en las dos últimas décadas del siglo XIV la presión sobre la mermada población se afloja un poco, lo cual permite una lenta y paciente reconstrucción de los hogares. Es cierto que hay menos familias, pero se presentan más nutridas y dotadas de animales. De modo que los hogares enteros aumentan en la misma proporción que disminuyen los desestructurados, encabezados por huérfanos, viudas, o solteras.

${ }^{46}$ En el siglo XIV contabilizamos un total de 105 documentos (compra ventas y donaciones) efectuadas entre el cabildo, o algún canónigo particular, y fieles laicos de la ciudad de Pamplona. De ellos 23 son protagonizados por viudas lo que supone un $21,90 \%$ del total.

${ }^{47}$ Equip Broida 1984, p. 28.

${ }^{48}$ Aparecen vendiendo sus bienes como el caso de Sancha Ocariz y su hijo Pascual Miguel podador, vecinos de la Navarrería, que venden a otros vecinos del mismo burgo, media casa por 70 sueldos (31 julio 1351). CCP, 1331. Curiosamente, a esta misma mujer la vemos en 1352 comprando media casa en Pamplona por la misma cantidad recibida (CCP, 1338).
} 
indicara lo contrario ${ }^{49}$. Pero a pesar de contraer unas segundas nupcias el estado de viudedad, experimentado por una mujer, y su condición social adquirida por ello, le acompañaría toda su vida. La viudedad marcaba en la vida de una mujer un antes y un después.

Como acabamos de decir muchas viudas volvían a contraer matrimonio, aunque en este caso debía autodotarse. No hay que perder de vista que para las mujeres es de vital importancia social la asociación a un varón, ya que esta es la figura que les otorga el lugar que ocupan en la organización social a la que pertenecen ${ }^{50}$. No obstante, en este sentido hemos de advertir de las reticencias de la época a que la mujer contrajera un segundo matrimonio y era más habitual en el caso de viudas jóvenes ${ }^{51}$. Este parece ser el caso de Teresa Ortiz de Mendillorri. La primera evidencia documental de esta mujer es del año 1303, en un documento que se redacta en sus propios palacios de Mendillorri. En ese año funda una capellanía perpetua en la catedral y pide ser enterrada en la sepultura de sus padres situada en el claustro, dejando para su sostenimiento lo que debía ser su herencia:

los mios palacios de Mendillorri y la torre, un huerto de nueue piezas de tierra, la viña, la pedrera sacada et por saccar....la meatad de toda la ostilla de casa, de cubos, cubas, archas, ropa de lino, de lana et de seda, de cobre, de fierro et de metal et de fusta... todo cuanto tiene en la villa y terminos de Mendillorri en possesiones et en muebles.

Al mismo tiempo, deja a la pitancería para el sostenimiento de una pitanza anual de los canónigos y para la remisión de sus pecados todos los bienes que tiene en el término de $\mathrm{Oroz}^{52}$. No obstante, en poco más de un año se redacta un nuevo documento: su testamento. En esta ocasión comienza diciendo que cuenta con la aprobación del que ahora es su marido, Miguel Ortiz de Zulueta. Entendemos que es su segundo cónyuge, y que esta mujer era viuda pues al final de este documento hace referencia a Pero Lopiz marido

\footnotetext{
${ }^{49}$ Segura 1986, p. 126. Así por ejemplo hemos encontrado un documento (29 septiembre 1314) donde Sancha Martínez de Gazolaz vende a la pitancería ocho cahíces y dos robos de trigo de collazos porque eran sus bienes dotales (CCP, 1009).

${ }^{50}$ Val Valdivieso 2004b, p. 110.

${ }^{51}$ Pérez de Tudela 2000, p. 295.

${ }^{52}$ ACP, HH 5: "et quiero et mando destinando que el prior de Sancta Maria de Pamplona ponga el capeillan tal que sea honesto qui cante la dicha missa de requiem...Item que salga los dias acostumbrados de sallir sobre la nostra fuessa con laguoa beneita a fazer et dizir oracon por las dichas animas. Et que mantienga et prouea al dicho capeillan honestament en comer, en beuer, et en vestir, et en calçar, et en sus cosas necesarias. Et que biua el dicho capeillan en las casas del priorado de Santa Maria de Pamplona. Et que seguezta de noche et de dia todas las horas dentro en el choro de Santa Maria de Pomplona con los canonigos".
} 
mio que fue y al que no mencionó en su primer documento quizás por no estar aún casada. Siguiendo esta hipótesis esta mujer en un breve espacio de tiempo se casa, enviuda y vuelve a casar. Cabe pensar que a raíz de cada uno de sus matrimonios redacta un nuevo testamento, guardando entre uno y otro el año de luto correspondiente y tradicionalmente establecido. Este segundo matrimonio lo ha debido contraer entre 28 junio de 1303 y 24 septiembre de 1304 , fechas de ambos documentos, y ahora establece que la donación de sus propiedades se haga cuando fallezca ella y también su segundo marido. Además, la capellanía fundada ya no es sólo por el bien de su alma, sino que incluye a su segundo marido al que quizás ha elegido ella. Sus donaciones a favor de la catedral se incrementan, dejando al hospital de San Miguel, destinado a acoger pobres y enfermos, unas viñas; a la pitancería sus bienes en Eriete para el sostenimiento de un aniversario por ella y su marido; y manda a sus cabezaleros que compren un baldoquin pora offreçer con mi cuerpo al altar de Sancta Maria de Pamplona; lega al arcediano de la tabla unos casales que eran de su primer marido y al priorado: la meatat de la ostilla al dicho priorado pora enpues dias de Miguel Ortiz como de cubos et de cubas et de archas ${ }^{53}$.

Las donaciones son la primera evidencia material de las relaciones entre el cabildo y este grupo de mujeres. Además, a raíz de la lectura de la documentación parece claro admitir que muchas de las donaciones obedecen evidentemente a una especial relación de los donantes, con el cabildo en su conjunto y el templo catedralicio, o bien con un canónigo particular al que le muestran su gratitud. Es el caso de Sancha Pérez, viuda del pellejero Semen de Artajona. Esta mujer en 1312 va a dejar unas casas que tiene dentro de los palacios de Guerez, situados junto al cementerio de la catedral, al canónigo Semen Semeneitz de Biuezal, y nos explica la razón de tal cesión:

por muchos servicios et plazeres agradables que vos el honrado et cuerdo varon don Semen Semeniz de Bioçal canonigo de Pamplona auedes fecho ami en muchas maneras et nombradament encantar missas por la anyma de doyna Gracia mi tia que fue aquien Dios perdone que cantastes por qoatroaynos et mas quando era capellan seglar. Et por esta razon queriendo vos dar galardón segunt mi poderio es do et fago donadio ${ }^{54}$.

También podría ser el caso de Sancha Martínez de Maquirriain, esta mujer aún en vida de su marido, dona en el año 1309 al arcediano de la cámara, Semen García de Asiáin, varias posesiones (palacios, casas y collazos)

\footnotetext{
${ }^{53} \mathrm{ACP}, \mathrm{T} 8$.

${ }^{54} \mathrm{ACP}, \mathrm{R} 36$. Este canónigo en 1318 funda una capellanía y para su sostenimiento deja estas casas recibidas en donación.
} 
en Añorbe. En esta carta de donación se funda también un aniversario ${ }^{55}$. Al año siguiente, el canónigo pitancero toma posesión de los bienes dejados en Larrain para el sostenimiento de ese aniversario, por lo que cabe pensar que su marido Iñigo Pérez de Sansoain, escudero, había fallecido ${ }^{56}$. Además, en un documento posterior, fechado el 14 septiembre de 1311, el procurador de Sancha, Juan Martínez de Sansoain, con toda probabilidad pariente del difunto esposo, confiesa que Sancha ha recibido los 40 cahíces de trigo que el arcediano de la cámara le debía. Un dato que evidencia la situación de cierta protección "pactada" entre el cabildo y esta mujer viuda.

De manera que son donaciones gratuitas movidas por fines o consideraciones espirituales, en gratitud a servicios prestados o con esperanzas en oraciones y mediaciones futuras. Una relación similar es la que manifiesta mantener Estefanía, la viuda del panadero don Miguel de Larraotz. Aún en vida de su marido, el matrimonio decidió donar al canónigo hospitalero, don Sancho Martínez de Guerguetain, la casa que ellos tenían en la rua dela broteria uieilla del borc de Sant Cernin de Pamplona con la mitat de la hostilla que nos auem en la dita casa de ferr et de fusta, de cuyvre et de metal. El motivo de tal donación lo manifiesta Estefanía ya viuda en un documento fechado el 8 mayo 1327: per moltz plazeres et agradables seruicis que lo dit hospitaler a nos a fait. Además, en esta misma carta de donación, la viuda declara como hasta el día presente, el hospitalero sigue manteniendo su compromiso de darle mientras viva: cinç quafiz de formet et cada tres quoques de most et sengles portc ${ }^{57}$. Esta donación se puede identificar con un gesto piadoso a favor de los pobres atendidos en ese hospital, pero también permite vislumbrar una relación más estrecha con la comunidad religiosa que mueve a realizar este gesto oneroso con el que apoyar al cabildo y su labor asistencial. En contrapartida la viuda recibe pan, mosto y carne de cerdo del canónigo hospitalero, lo cual la asemeja a una paniaguada del Hospital aunque en la documentación no recibe tal nombre. A su muerte en 1328 las propiedades, en concreto las casas, pasan por orden del hospitalero a la pitancería pues la intención era fundar un aniversario por el bien del alma de la difunta.

Unos compromisos similares adquiría el cabildo con aquellas mujeres paniaguadas, que hacen entregan de sus bienes a cambio de recibir sustento todos los días de su vida por parte de la institución canonical. Estaríamos ante un segundo modo de establecer relación con el cabildo, aunque en muchos casos tras el término paniaguada desconocemos si se trata de mujeres solteras

${ }^{55} \mathrm{ACP}, \mathrm{M} 47$.

${ }^{56}$ ACP, M 56.

${ }^{57}$ ACP, I Hospit. 15. 
o viudas ${ }^{58}$. Este tipo de mujeres podría incluirse desde el punto de vista de la espiritualidad en el término de mulieres religiosae. Es decir aquellas que vivían una vida religiosa al margen de las instituciones y reglas monásticas y que se dedicaban en diversos grados y maneras a una vida a un tiempo activa y contemplativa, y cuyas fronteras a veces no resultan nada fácil de establecer confundiéndose con reclusas, ermitañas y terciarias... ${ }^{59}$ Así en 1345, Teresa de Puente la Reina, paneagoada en el priorado de Sancta Maria de Pamplo$n a$, dona dos viñas que tiene en el término de Ezcaba para que

despues que deueniere de mi que hayan asaylir cada ayno mientre el mundo durare sobre mi fuessa todos los canonigos dela dicha eglesia de Sancta Maria aqueyllos que sean por tiempo segunt que han usado e costumbrado de saylir en semeiable caso ${ }^{60}$.

De este modo esta mujer que había confiado su vida material en manos de los canónigos, hace ahora también lo mismo con su vida eterna, fundando un aniversario en la catedral. Este gesto era muy común también entre las beatas, fenómeno de vida propio de los siglos XIV y XV, más ligado a la espiritualidad mendicante. Estas favorecían las instituciones con donaciones con reserva de usufructo lo cual implicaba garantizarse su subsistencia, aunque ellas no suelen abandonar su casa. Y este tipo de donaciones podía ser indicativo de una involucración más estrecha entre las beatas y los monasterios o instituciones eclesiásticas ${ }^{61}$.

En algunos casos la vinculación o la relación con el cabildo se había establecido de manera natural e incluso antes de llegar al estado de viudedad. Este sería el caso de María Lopiz, viuda del que había sido el campanero de la catedral, García de Miguel. María, convertida en administradora y usufructuaria de los bienes de su esposo, decide a comienzos de 1341 comprar a los hijos de un mercader franco una viña situada en Pamplona ${ }^{62}$. En el mes de mayo de ese mismo año dona esta viña al cabildo, a la pitancería, para el sostenimiento de una fundación

${ }^{58}$ Los paniaguados realizan una acción de entrega de su persona, cuerpo y alma, y bienes a la institución eclesiástica en cuestión. Esta a su vez los recibe y les hace partícipe tanto de los bienes materiales, casa y sustento, como espirituales de la comunidad.

${ }^{59}$ Garí 2013,p. 359.

${ }^{60}$ ACP, P 4. Estas viñas fueron compradas por Teresa el 16 febrero de 1337 (CCP, 1236).

${ }^{61}$ Graña 2013, pp. 379-380. El término beata no aparece en la documentación estudiada, el más similar es el de emparedadas o reclusas que vivían en la cuenca de Pamplona llegando en el siglo XIII a ser un centenar. Pavón, García de la Borbolla, Dulska 2017, p. 98; Cavero 2010, pp. 139-142.

${ }^{62}$ García Herrero 1990, p. 334. Las viudas de las ciudades constituyen el grupo femenino que más inmerso se encuentra en el ajetreo económico urbano. 
pro anima: mantengades para todos tiempos del mundo una lampada que queme de noche et de di ante laltar de Ihesu Cristi, que es dentro cerca el dormiterio uestro. Et que seades tenidos de dar et dedes cinquo sueldos de sanchetes o tornese chicos cada ayno enla prima bona noche al dormitorero uestro qui agora es hosera por tiempo. Que encienda la dicha lampada quando mester fiziere por secula cuncta.... Et encara que seades tenidos de fazer et fagades cada ayno por secula cuncta, un aniuerssario segunt auedes usado et acostumbrado de fazer. Aniuerssario por la anima del sobredicho don Garcia Miguel mi marido. Et empues mis días, por la mia et de mis defunctos et por las animas fieles en aquyl dia que nos otros terredes por bien ${ }^{63}$.

En definitiva, deposita con confianza en los canónigos la salud eterna de su difunto marido y de su alma ${ }^{64}$.

Cabe pensar que las actuaciones piadosas de estas mujeres que en cierto modo se encuentran desamparadas y desprotegidas, sin la figura del marido, pueden ser indicativas de una relación previa de confianza, de garantía y protección espiritual que se manifiesta en unas disposiciones post mortem. Otro caso similar es el de Bona Murde, viuda del mercader Martín de Arbea, que indica que a su muerte la pitancería tome posesión de una viña que tiene en Villaba para mantener et fazer mantener deoues de nudeueniere un aniuerssario cadaynno mientres el mundo durare como es usado et acostumbrado de mantener aniuerssario en la dicha eglesia de Sancta Maria ${ }^{65}$. Esta misma viuda aparece en otro documento fechado con anterioridad, el 5 enero 1340, vendiendo a un vecino de la Navarrería Iñigo Lopez de Espoz una viña en Lezcayru. Una operación que nos ilustra su dinamismo y su iniciativa en temas económicos ${ }^{66}$. Podemos pensar que muchas de estas viudas son mujeres que quizás han aprendido esta dinámica económica de sus esposos, que han colaborado con ellos en vida y que tras su muerte, protagonizan operaciones mercantiles en solitario.

\footnotetext{
${ }^{63} \mathrm{ACP}, \mathrm{O} 5$.

${ }^{64}$ Es normal pensar que los personajes que trabajaban al servicio de los canónigos acudirían a ellos en el momento de la encomendación de su salvación eterna. Otro ejemplo es el caso del dormitorero de los canónigos, Pero Martínez de Piedramillera que en 1323 dona al cabildo una viña en Pamplona con obligación de un aniversario (ACP, O 12).

${ }^{65}$ ACP, M 6 (1 febrero 1348). Esta mujer aparece junto a su marido comprando una viña en Pamplona, en el término de Ovieta, por 90 libras al matrimonio formado por Sancho Pérez de Aldaba y Gracia Azanza (31 enero 1302). CCP, 884.

${ }^{66} \mathrm{CCP}, 1255$. Este vecino de la Navarrería donará en 1341 una viña pero que dice comprada en subasta pública al cabildo para participar de sus bienes espirituales. Además, se conserva su testamento fechado 17 julio 1348 en el que funda dos capellanías (CCP, 1321). Finalmente, en 1375 el cabildo toma seis casas para el mantenimiento de esa capellanía y aniversario (CCP, 1493 y 1600).
} 
Junto a las donaciones y también con la finalidad de ayudar al sostenimiento de la pitancería se encuentran algunas ventas de propiedades al cabildo como la que hace Prima del Hospital, la viuda de don Pere Martín del Hospital, junto a sus dos hijos Catalina y Martín. En esta ocasión la venta se hace al pitancero Martín Pérez de los Arcos, 27 mayo de 1303, y se indica que se hace para obs ala dicta pitanceria de santa Maria ${ }^{67}$. A nuestro juicio esta operación comercial encierra una relación con el cabildo pues el documento en muchas ocasiones indica el destino de tal venta, y generalmente se trata del sostenimiento de alguna capellanía de algún canónigo difunto. Es el caso de la viuda María Pérez de Eransu quien junto a su hijo venden al canónigo pitancero Martín Sánchez de Arteiz la pecha de siete cahíces y dos robos de trigo en los lugares de Urrizola, Ecay, Ilarrazu y Arraiza, para la capellanía del fallecido arcediano de Valdeaibar Yénego Garceizt de Huarte ${ }^{68}$. Unos años más tarde, en 1324, encontramos a otra viuda, Estefanía, muyller de don Semeno de Viscarret Ferrer vezin de Pampalona qui fo, y a su hijo vendiendo al canónigo pitancero una viña en Burlada llamada la Morea, para el sostenimiento de esta misma capellanía ${ }^{69}$. Y en 1377, Simona, viuda de García Oyalde, vecino de la Navarrería de Pamplona, vende al canónigo pitancero una viña junto a la Navarrería por 7 libras para el aniversario del canónigo difunto Sancho $\mathrm{Oroz}^{70}$. Esta práctica debía ser bastante frecuente y recorre toda esta centuria, pudiendo concluir la existencia de una relación más personal y una especial cercanía entre estos vecinos del tejido pamplonés y el clero capitular.

La iniciativa de buscar sostener los gastos de la comunidad canonical, ya sea la pitancería y sus fundaciones piadosas, o el hospital de San Miguel que asiste a pobres, es por lo tanto otro modo de establecer relaciones con el cabildo catedralicio o bien manifestación de relaciones ya existentes. En 1328 Isabel de Aoiz, viuda del zapatero vecino de Pamplona, Miguel de Aoiz, y su hijo, heredero también del oficio de su padre, el zapatero Iohan Miguel de Aoiz venden a Martín Ochoa de Villanueva, canónigo y procurador del cabildo, una viña que tienen en Beloso y un anillo de oro con su piedra preciosa valorado en 20 libras: pora huebos dela chantria dela yglesia de

\footnotetext{
${ }^{67} \mathrm{ACP}, \mathrm{P} 23$. Otro caso de venta a canónigos concretos es el de la viuda Elvira Elizamendía quien con el consentimiento de sus hijos venden sus palacios, collazos, casas, piezas y demás bienes en Arisztaray por 17 libras ACP, L 30 (22 enero 1313). El 1 agosto de 1314 sus hijos ratifican la venta hecha por su madre y se obligan a no contradecirla (CCP, 1007).

${ }^{68}$ ACP, L 25 (14 octubre 1315).

${ }^{69}$ ACP, O 4. Otro ejemplo, de venta para "complacer" una capellanía en este caso del arcediano de Usún difunto, Juan Pérez de Estella, es el que hace doña Gracia de Urdoz mujer del zapatero Lop de Azanza, ACP, O 31 (año 1338).

${ }^{70} \mathrm{ACP}, \mathrm{P} 6$.
} 
Sancta Maria de Pamplona ${ }^{71}$. En este caso, como en muchos otros hay que anotar otro hecho que revela la importante posición de la viuda como tutora de la prole. Nos referimos a la necesidad que tenían los hijos de solicitar el consentimiento de su madre en la realización de negocios diversos para los cuales eran menores legalmente ${ }^{72}$. No obstante, siempre estará por delante el interés de los integrantes de la familia, de manera que la viuda habrá de actuar en todo momento en beneficio de estos sin olvidar su posición. Este es un claro caso de como la viuda y sus hijos que mantienen la actividad profesional del padre, lo cual en cierto sentido constituye una garantía para la mujer enviudada, desempeña una gestión eficaz económica del patrimonio, y que la convertiría en un elemento activo de esa oligarquía urbana dedicada fundamentalmente a esas actividades artesanales y comerciales ${ }^{73}$. Además ella es la trasmisora de derechos, bienes y honores, también de los saberes tradicionales y de la memoria de la familia que pasan de generación a generación por vía femenina, y en este complejo papel se encuentran inmersas ${ }^{74}$.

Por otro lado, no debemos olvidar la situación de desamparo en la que se debían encontrar muchas viudas, sobre todo al inicio de su viudedad, cuando tienen que empezar a administrar el patrimonio familiar, donde la ausencia del cónyuge y por tanto del trabajo directo implicaría una ausencia de ingresos, de liquidez necesaria para el mantenimiento de su familia. La viuda se convierte de la noche a la mañana en gestora, administradora y en algunos casos incluso debe responder a las deudas de su marido. De manera que además de empezar a administrar el patrimonio familiar, sus derechos y obligaciones, debían responsabilizarse del legado financiero de su difunto marido, lo que podía empeorar notablemente su situación ${ }^{75}$. En algunos casos el problema para su salida económica es que los bienes se encontraban cargados de deudas y la viuda debía irlas saldando ${ }^{76}$. Este es el caso de Gracia Sánchez de Montagut condenada en 1347 junto a su hija a pagar la suma de 600 libras al canónigo Pedro de Olloqui ${ }^{77}$ que es también su cuñado, en razón

${ }^{71}$ ACP, I Cantoris, 37, 95.

${ }^{72}$ Rojo 1987, p. 132.

${ }^{73}$ Ramírez-Vaquero 2009, p. 135. Los zapateros constituían la cuarta ocupación profesional más numerosas documentada en los tres burgos de Pamplona, incluso una de las calles del burgo de san Nicolás refleja su importancia, siendo por lo tanto parte de la oligarquía urbana de la ciudad. No hemos de olvidar que es una ciudad transitada por peregrinos a Santiago y muchos artesanos se dedicarán a proveer del material más necesario para esa peregrinación.

${ }^{74}$ Val Valdilvieso 2004b, p. 124.

${ }^{75}$ Carvajal 2004, p. 132.

${ }^{76}$ García Herrero 1990, p. 354.

${ }^{77}$ Este canónigo documentado desde 1318 y que fue también maestro de obras de la catedral hacia 1351, recorre un largo camino en el seno del cabildo. Fue hospitalero y en 1360 pasa a ocupar el arcedianato de la Tabla hasta las últimas décadas del siglo XIV (1372). 
de una escritura firmada por su marido en $1342^{78}$. Estamos ante una familia de la que sabemos algo de sus orígenes sociales por el propio testamento fechado en 1346 de Gracia y su marido Martín Mendia, escudero. El documento nos informa que el esposo es hijo de un caballero llamado don Miguel García de Oylloqui. A este último Carlos II le encomienda la guarda del castillo de Liquin cerca de Urroz en el año $1351^{79}$. Pero tampoco olvidemos que entre los barones que asisten a la coronación de Carlos II en 1350 se encontraba Martín García de Olloqui ${ }^{80}$, por lo que estamos ante una familia de alta estirpe en el reino. De manera que estamos ante un caso que pone en evidencia la existencia de vínculos familiares entre los canónigos y las familias de la nobleza local que ocuparon puestos de responsabilidad en el reino.

Un rasgo que parece ser común en todas estas mujeres es su denodado esfuerzo por mantener la estabilidad de su patrimonio por pequeño que fuera ante las adversas condiciones que podían sobrevenir si el hombre de la casa o el cabeza de familia desaparecía como garante de ingresos de la unidad familiar $^{81}$. Esta circunstancia es la que se observa en el siguiente documento, donde la viuda tiene que acudir a ayudas y préstamos empeñando para ello algunas de sus propiedades. Los protagonistas son: por un lado, la viuda María Pérez de Guevara, esposa del caballero difunto Miguel Sanz de Arbide, junto a sus hijos Sancho Miguel y Miguel Sanz; y por el otro, el canónigo Semen Semeneitz de Bigüezal. Los primeros reconocen un préstamo de 15 libras recibido del canónigo citado: en plana amor sin husura nin barata ninguna. En virtud de tal "auxilio" la viuda y sus hijos establecen que mientras ellos tengan ese capital conceden al canónigo la tenencia de unas casas y collazos localizados en Sanguariz: auemos uos dado empeynios hi en tenencia apoderando a uos et desapoderando anos aqueyllas casas que nos auemos en la villa de Sanguariz... otrossi los coyllaços et coyllaças que nos auemos en la dicha de Sanguariz ${ }^{82}$. Una situación similar parece repetirse en el caso de María Semenez de Zariquieta, viuda del zapatero García Martín de Turrillas ${ }^{83}$. Esta

\footnotetext{
${ }^{78}$ CCP, 1311. En 1343 su marido, Martín de Mendía declara que ha recibido de este último la suma de 400 libras y se obliga a devolverlas (CCP, 1288). Pero en su testamento (ACP, Tabla, 14), solo deja al hospitalero 20 libras. Además de otras mandas para la catedral como: "cient sueldos pora poner detalles, çyrios, como de cada dia manden ante la iglessa de Santa Maria de Pamplona, en remyssion de nuestros pecados. Item otrossi hordenamos et mandamos et leyssamos a las dueynas de San Miguel de Pamplona çincoanta sueldos pora vna pytança”.

${ }^{79}$ CAGN, Comptos, vol. II, doc 357.

${ }^{80}$ Zabalo 1973, p. 210. Tenemos documentado por estas fechas a un escudero llamado Lope García de Olloqui. CAGN, Comptos, vol. II, doc. 577

${ }^{81}$ Carvajal 2004, p. 121.

${ }^{82}$ ACP, L 18 (13 agosto 1315).

${ }^{83}$ Está documentado un zapatero Lopez de Turrillas que forma parte del Consejo de los doce en el burgo de San Nicolás. Ramírez-Vaquero 2009, p. 135.
} 
mujer en un documento fechado 10 junio 1372 manifiesta que: reçibido et tengo engoarda et en fiel comienda a saber es del honrado et religioso don Semeno de Çarequieta canonigo en la eglesia de Sancta Maria de Pomplona cinquonta et siete libras de bonos dineros karlines prietos. En este caso el apellido topónimo de la viuda y el canónigo nos pueden llevar a pensar en una relación no sólo de vecindad, sino también de parentesco, una vez más se evidencia el cabildo como esfera de proyección social de la burguesía, que facilitara cierto socorro económico, que en un momento puntual realiza el canónigo para aliviar alguna deuda o necesidad de la viuda y que ella deberá devolver ${ }^{84}$.

Por lo tanto, estamos ante un nuevo nexo de relación donde el cabildo o algún canónigo en particular aparecen como "auxilios" financieros que permiten solventar el empobrecimiento inmediato ante el cual muchas de estas mujeres se veían abocadas. Así muchas de estas mujeres, aunque fueran de condición social más elevada, esposas de caballeros, se ven obligadas a endeudarse o vender propiedades con la finalidad de obtener liquidez con la que afrontar el día a día de sus familias. El 12 febrero 1316, Juliana Martínez de Echalaz, viuda del caballero Miguel de Guerez probablemente desde el año 1307, año en el que se establece la tutoría de sus hijos al caballero Pedro García de $\mathrm{Aniz}^{85}$, va a vender junto a sus hijos los palacios, casas, casales, el corral y el huerto llamados de Guerez, situados cerca del cementerio de la catedral de Pamplona, por un valor de 65 libras. En esta ocasión el comprador no es un miembro del cabildo aunque si un personaje vinculado al servicio de la catedral: Sancho Miguel de Sansoain, encargado de la luminaria de Santa María de Pamplona ${ }^{86}$. Y este puede ser también el caso de la viuda del mercader Pere del Pont, María, vecina de la Navarrería, quien en 1362 decide vender la mitad de la casa que tiene en la rúa Mayor de este burgo al chantre de la catedral don Guillen de Amaneu por 52 libras $^{87}$.

Como hemos ido viendo muchas de estas viudas que se relacionan con los canónigos parecen formar parte de las oligarquías urbanas, esposas de caballeros o de mercaderes en su mayoría. No cabe duda de que existe una

\footnotetext{
${ }^{84}$ ACP, H 43. También en 1308 la viuda de Arnaut Chaboru, da a Semen García de Asiain, arcediano de la cámara, una casa en San Sebastián por el alma de su marido y por 3000 maravedíes de Castilla que el arcediano le había prestado. (ACP, Cámara 12).

${ }^{85} \mathrm{ACP}, \mathrm{S} 31$. En esta venta también figura otro personaje, el caballero don pedro García de Yanitz, tutor de los hijos de la viuda que da su consentimiento. Esta tutoría estaba establecida desde 1307 por el gobernador de Navarra Guillen de Chaudenay (CCP, 925). Recordemos que, si el marido muere dejando hijos menores de siete años, los parientes del padre pueden tomar a los hijos y todo lo del padre y criarlos hasta la edad de siete años.

${ }^{86} \mathrm{Se}$ conserva el testamento del Sancho Miguel de Sansoain fechado en 1335 y que contiene generosas mandas pías para la catedral de Pamplona. Por otro lado, en 1343 encontramos a un tal Pascual Sanz vendiendo estas mismas propiedades al canónigo Pero Pérez de Itoiz.

${ }^{87} \mathrm{ACP}, \mathrm{T} 4$.
} 
clara estrategia mantenida en casi todos los cabildos por parte de las familias nobles y las oligarquías urbanas en colocar a algunos de sus miembros en el cabildo. Y para llegar a ello los nexos de unión deben irse entretejiendo poco a poco, desde la simple vecindad a unas relaciones interpersonales estrechas que permitan en algún momento la inclusión de alguno de sus miembros entre las filas del clero más destacado de la ciudad.

A modo de conclusión y en relación también con esas vinculaciones propiciadas por lazos de parentesco establecidos y que han llegado hasta el cabildo sirva como ejemplo el siguiente episodio fechado el último día del año 1383 y que tuvo lugar en el claustro de la catedral de Pamplona, en concreto delante de la sepultura del obispo Arnaldo de Barbazán. Están presentes Bona Darbea, una mujer de origen franco, viuda del mercader don Pere de $\mathrm{Ytoyz}^{88}$, y su hija Elvira, junto a ellas, el prior Juan de Etunain y los canónigos pitanceros, García de Bruslada y Xemeno de Aibar. Esta escena nos deja una rica evidencia documental de la labor litúrgica desempeñada por los canónigos en la iglesia mayor de la ciudad de Pamplona. Pero también muestra el interés de esta mujer y su deseo de sostener ese culto divino, lo cual nos sugiere una vinculación personal y espiritual con la comunidad canonical:

considerando los grandes seruicios que por los seynores calonges et otros seruidores de la dicta eglesia de Pamplona se fazen en la dicta eglesia en el diuinal officio a honor de Dios et de la Uirgen sancta Maria, et queriendo segunt mi poder acrescentar et sostener el dicto diuinal officio. Assi bien queriendo proueer a la salut de mi anima et de Eluira de Ytoiz mi fija que es present, et alas otras animas ami et a la dicta mi fija acomendadas. En presençia de uos los hondrados et religiosos mossen Iohan de Etunayn, maestro en theologia, prior, de don Garçia de Bruslada, et de don Xemeno de Ayuart, canonigos et pitanceros de la dicta iglesia. De çierta sciencia et de mi agradable uoluntad, et con consentimiento de la dicta Eluira... do liberalment a la pitanceria de la dicta iglesia, aqueilla vina de diez et ocho arienços que yo he... para que los pitanceros sean tenidos de espender toda la renta dela dicta vina en capellanías. Es asaber en pagar a los capeyllanes que por tiempo seruiran en el coro de la dicha eglesia et non hayan a espender en otros usos ${ }^{89}$.

Lo interesante de este último ejemplo, es señalar como esta relación con el cabildo puede estar también sujeta y provocada por ciertos vínculos de

${ }^{88}$ En 1335 vemos a un tal Pere de Itoiz, mercader franco que aparece en el documento como cabezalero de la viuda de un platero, haciendo negocios con este canónigo. ACP, N 1. De manera que esta mujer puede ser pariente del canónigo Pero Pérez de Itoiz que prácticamente vive todo el episcopado de Arnaldo de Barbazán.

${ }^{89}$ ACP, N 1. 
consanguineidad. Entre 1318-1348 tenemos documentado a un canónigo de nombre, Pero Pérez de Itoiz, probablemente hijo de un mercader franco llamado Pero de Itoiz. Este último aparece en 1335 como cabezalero de la viuda de un platero haciendo negocios con este canónig $0^{90}$. Han pasado cincuenta años y la familia vuelve a aparecer relacionada con el cabildo y son una evidencia de como la burguesía local logró en muchas ocasiones desde el siglo XIII la promoción de sus miembros a las dignidades capitulares y que es sin lugar a dudas otra de las evidencias de la proyección del cabildo en el tejido social de la ciudad de Pamplona.

\section{CONSIDERACIONES FINALES}

En suma, frente a imágenes heredadas o que nos hemos podido forjar de mujeres medievales ocultas y pasivas, la documentación nos sigue reflejando una realidad que modifica esos modelos. Y así emergen entre los pergaminos mujeres que ya sea por su destino biográfico quedan viudas o mujeres que no lo están ${ }^{91}$, que manifiestan en sus actuaciones en la vida pública, iniciativa, capacidad gestora, visión empresarial y desde luego responsabilidad y defensa de sus intereses y de los intereses de los suyos.

En estas páginas hemos intentado reflejar la situación y vida de unas mujeres que, por su nueva condición, marcada por un hecho importante en sus vidas, la pérdida del marido, se convierten no sólo en meras usufructuarias de los bienes de sus esposos, sino que se estrenan en un nuevo papel de administradoras y gestoras de un patrimonio cuya finalidad no es otra que garantizar una estabilidad tanto a ella como a sus descendientes. Muchas de ellas podrán mantener su estatus social en parte gracias a la continuidad de la actividad profesional de sus maridos, unos negocios y oficios que trasmiten a sus hijos, lo cual les sigue definiendo como miembros de la oligarquía urbana. Otras verían significativamente empeorada su situación económica, bien por las deudas que heredan, bien por la falta de expectativas profesionales, lo cual les lleva a buscar una inmediata liquidez, vendiendo posesiones, para afrontar la vida a corto y medio plazo. Finalmente, no unas pocas unirían al dolor de la pérdida, que provocaba instantáneamente una situación de desam-

\footnotetext{
${ }^{90} \mathrm{ACP}, \mathrm{N} 17$ y N 34. Quizás estas relaciones comerciales pueden implicar cierta cercanía con la institución canonial donde profesaba su hijo.

${ }^{91}$ Un caso significativo es el de Catalina de Burgos vecina de Pamplona, quien en 1377 cede a Guillén de Broa, arcediano de Usún una casa y huerto en la calle San Agustín por 20 libras. El documento nos dice que Catalina había adquirido esta propiedad un tiempo antes por una compra que ella misma hace a "Dona Anglesa muger de Renalt de caorz estaynero vezinal de la ciudat et Nauarreria de Pamplona". Dos mujeres que hacen negocios en pleno siglo XIV.
} 
paro, una situación de empobrecimiento, estas acudirán al amparo, consuelo y refugio de la institución canonical. En este sentido y bajo el episcopado de Arnaldo de Barbazán, se constituye en la catedral la cofradía del Santísimo o Corpus Christi (1327) cuyo fin era el culto eucarístico pero también fruto de la caridad ejercía una función de acogida y asistencia a viudas pobres a través de tres casas, asilos, destinados a ello ${ }^{92}$.

En esta nueva vida que se les ponía por delante, las viudas urbanas van a establecer de manera autónoma relaciones sociales, y unos agentes a los que parecen aproximarse es el clero de la ciudad. Así en particular hemos analizado las evidencias documentales que nos permiten establecer una particular e individual relación de estas mujeres con el cabildo de la catedral de Pamplona. Las donaciones para sostener fundaciones piadosas post mortem o solventar las necesidades de estos clérigos; las ventas destinadas en su mayoría al sostenimiento de capellanías y aniversarios de canónigos difuntos han sido los exponentes más numerosos. No obstante, a nuestro juicio cabe pensar que muchas de estas mujeres, que además deciden no volver a contraer matrimonio en su mayoría, van a optar por una vida espiritual y religiosa más intensa, donde se impone la preocupación por la salvación eterna y por lo tanto la participación en los méritos de la comunidad religiosa. Así, aunque no abandonan su condición laical renuncian al mundo a lo material, mediante donaciones, y se dedican a una vida religiosa y a recibir bienes espirituales y subsistencia material por parte del cabildo.

En suma y a nuestro juicio, estas mujeres toman decisiones en cuanto a su patrimonio que obedece a unas razones que escapan a los rígidos esquemas mercantilistas, y que las vinculan en una relación que pensamos va más allá de la propia vecindad con el clero de la catedral de Pamplona y en muchos casos a sus vinculaciones consanguíneas. En este marco se deben entender las fundaciones piadosas, los préstamos, los sostenimientos de capellanías, las donaciones y quizás también las compraventas. En consecuencia se puede hablar de la existencia de unas relaciones personales, con un destacado componente espiritual, que en muchos casos convierten a la institución canonical en protectora de este sector social que podría encontrarse en una situación más vulnerable circunstancialmente: las viudas ${ }^{93}$.

\footnotetext{
${ }^{92}$ Núñez 1940, p.166. Las casas estaban situadas una en la calle Calderería con basílica propia dedicada a san Martín, otra en la calle compañía n 23 y la última en la Magdalena, derribada esta última en el siglo XVI por orden del Rey y por motivos militares. Las constituciones son de 1701 donde se manifiesta que la cofradía se sostenía también con limosnas de los vecinos y que las viudas debían rezar todas las noches el rosario juntas.

${ }^{93}$ Así por ejemplo, en 1385 el cabildo arrienda una casa en la rúa mayor a una vecina de la Navarrería, la costurera Pascuala García de Elcano Y en el contrato de arrendamiento exime a esta mujer de hacer cualquier obra o reparación en dicha propiedad como era habitual en los
} 


\section{BIBLIOGRAFÍA CITADA}

Asenjo González, María (1990), La mujer y su entorno social en el fuero de Soria, en Las mujeres medievales y su ámbito jurídico. Actas de las II Jornadas de Investigación Interdisciplinaria, Madrid, Universidad Autónoma de Madrid, pp. $45-57$ ( $1^{\mathrm{a}}$ ed. 1983).

Berthe, Maurice (1984), Famines et épidémies dans la champagne navarraise à la fin du Moyen Age, vol. 1, París, SFIED.

Carrasco, Juan (1973), La población en Navarra en el siglo XIV, Pamplona, Universidad de Navarra.

Carvajal, David (2004), La mujer castellana a fines de la Edad Media: una firme defensora del patrimonio familiar, en Val Valdivieso, Isabel (coord.), La historia de las mujeres. Una revisión historiográfica, Valladolid, Universidad de Valladolid.

Castan, Guillermo; Dueñas, Salvador (2006), Revisión de la incidencia de la peste Negra (1348) en Navarra a través de un modelo matemático de población, "Studia histórica. Historia Medieval” 24, pp. 275-314.

Cavero, Gregoria (2010), Inclusa intra parietes. La reclusión voluntaria en la España medieval, Toulouse, Méridiennes.

Diez de Salazar, Luis (1990), La mujer vasco-navarra en la normativa jurídica (XII-XIV), en Las mujeres medievales y su ámbito jurídico. Actas de las II Jornadas de Investigación Interdisciplinaria, Madrid, Universidad Autónoma de Madrid, pp. 95-115.

Equip Broida (coord. por M. ${ }^{\text {a }}$ Teresa Vinyoles) (1984), La viudez, ¿triste o feliz estado? Las últimas voluntades de los barceloneses en torno a 1400, en Las mujeres en las ciudades medievales, Actas de las III Jornadas de Investigación Interdisciplinaria, Madrid, Universidad Autónoma de Madrid, Seminario de Estudios de la Mujer, pp. 27-41.

Fortún, Luis Javier (1994), La catedral y el poder político, en Jusué Simonena, Carmen (coord. literaria), La catedral de Pamplona, Pamplona, Caja de Ahorros de Navarra, vol. 1, pp. 81-90.

Galán, Mercedes (2004), El régimen de la propiedad en el Fuero General de Navarra, Fuero reducido y disposiciones de Corte, "Iura Vasconia" 1, pp. 45-102.

Gámez Cenzano, Cristina (1998), El enfermero de la catedral de Pamplona, "Príncipe de Viana" 59, pp. 745-762.

arrendamientos: "no seades tenida de fazer reparacion ninguna ala dicta casa saluando que seades tenida de poner tierra enlas cambras dela dicta casa quando fiziere menester tansolamente et no ninguna otra reparation" ( ACP, S 8). 
García de la Borbolla, Ángeles (2013), Algunas consideraciones sobre el cabildo de la catedral de Pamplona durante el episcopado de Arnaldo de Barbazán (1318-1355), "Medievalismo" 23, pp. 157-175.

García de la Borbolla, Ángeles (2016), El cabildo de la catedral de Pamplona y la Navarrería en la segunda mitad del siglo XIV: la creación de un condominio, "Edad Media" 17, pp. 255-273.

García Herrero, Carmen (1990), Las mujeres en Zaragoza en el siglo XV, Zaragoza, Ayuntamiento de Zaragoza.

García Herrero, Carmen; Pérez Galán, Cristina (coords.) (2014), Mujeres de la Edad Media: actividades políticas, socioeconómicas y culturales, Zaragoza, Institución Fernando el Católico - Diputación de Zaragoza.

García Rubio, Luis; Rubio Hernández, Luis (2000), La mujer murciana en la Baja Edad Media, Murcia, Universidad de Murcia.

Garí, Blanca (2013), La ciudad de las mujeres: redes de espiritualidad femenina y mundo urbano, en Solórzano Telechea, Jesús Ángel; Arizaga Bolumburu, Beatriz; Andrade, Amelia Aguiar (coords.), Ser mujer en la ciudad medieval europea, Logroño, Instituto de Estudios Riojanos, pp. 349-370.

Goñi Gaztambide, José (1965), Catálogo del Archivo de la catedral de Pamplona, Pamplona, Príncipe de Viana.

Goñi Gaztambide, José (1979), Historia de los obispos de Pamplona, vol. I, Pamplona, Eunsa.

Goñi Gaztambide, José (1994), Episcopado y cabildo, en Jusué Simonena, Carmen (coord. literaria), La catedral de Pamplona, Pamplona, Caja de Ahorros de Navarra, vol. I, pp. 33-77.

Goñi Gaztambide, José (1997), Colección diplomática del archivo de la catedral de Pamplona, Pamplona, Gobierno de Navarra.

Graña, María del Mar (2013), Beatas y monjas. Redes femeninas y reforma religiosa en la ciudad bajomedieval, en Solórzano Telechea, Jesús Ángel; Arízaga Bolumburu, Beatriz; Andrade, Amélia Aguiar (coords.), Ser mujer en la ciudad medieval europea, Logroño, Instituto de Estudios Riojanos, pp. 371-388.

Jiménez Gutiérrez, Francisco Javier (1992), El cabildo pamplonés en el siglo XIV. Un análisis prosopográfico, "Príncipe de Viana" 53/196, pp. 391-408.

Lop Otín, María José (2003), El cabildo catedralicio de la ciudad de Toledo en el siglo XV. Aspectos institucionales y sociológicos, Madrid, Fundación Ramón Areces. 
Martinena, José (1996), Reseña de la evolución urbana de Pamplona. Desde el siglo XI hasta el derribo de las murallas en 1915, "Príncipe de Viana" 57/207, pp. 143-176.

Monteano Peio (2002), La ira de Dios, los navarros en la era de la Peste (1348-1723), Pamplona, Pamiela.

Núñez de Cepeda, Marcelino (1940), La beneficencia en Navarra a través de los siglos, Pamplona, Escuelas Profesionales Salesianas.

Pavón, Julia; García de la Borbolla, Ángeles (2007), Morir en la Edad Media. La muerte en la Navarra medieval, Valencia, Universidad de Valencia.

Pavón, Julia; García de la Borbolla, Ángeles; Duslka, Ana (2017), Silencio tengan en claustra. Monacato femenino en la Navarra Medieval, Pamplona, Eunate.

Pérez de Tudela, Isabel (1984), La condición de viuda en el medievo castellano-leonés, en Las mujeres en las ciudades medievales. Actas de las III Jornadas de Investigación Interdisciplinaria, Madrid, Universidad Autónoma de Madrid, Seminario de Estudios de la Mujer, pp. 87-101.

Pérez de Tudela, Isabel (2000), Ancianidad, viudedad... El hombre medieval en su edad postrera, en La familia en la Edad Media. XI Semana de Estudios Medievales de Nájera, Logroño, Instituto Riojanos de Nájera, pp. 285-317.

Pérez González, Silvia (2005), La mujer en la Sevilla de finales de la Edad Media: solteras, casadas y vírgenes consagradas, Sevilla, Universidad de Sevilla - Ateneo de Sevilla.

Ramírez-Vaquero, Eloísa (2009), The First Urban Oligarchic Network in Navarre: Pamplona, 1100-1318, en Asenjo González, María (coord.), Oligarchy and Patronage in Late Medieval Spanish Urban Society, Turnhout, Brepols, pp. 117-152.

Rojo, Paloma (1987), La mujer extremeña en la Baja Edad Media: amor y muerte, Cáceres, Administración Pública.

Segura Graiño, Cristina (1986), Situación jurídica y realidad social de casadas y viudas, en Fonquerne, Yves-René; Esteban, Alfonso (eds.), La condición de la mujer en la Edad Media: actas del coloquio celebrado en la Casa de Velázquez, del 5 al 7 de noviembre de 1984, Madrid, Casa de Velázquez, pp. 121-133.

Solórzano Telechea, Jesús A.; Arizaga Bolumburu, Beatriz; Andrade, Amélia Aguiar (coords.), (2013), Ser mujer en la ciudad medieval europea, Logroño, Instituto de Estudios Riojanos.

Val Valdivieso, M. ${ }^{a}$ Isabel (coord.) (2004a), La historia de las mujeres. Una revisión historiográfica, Valladolid, Universidad de Valladolid. 
Val Valdivieso, M. ${ }^{a}$ Isabel (2004b), Las mujeres en el contexto de la familia bajomedieval. La corona de Castilla, en Trillo San José, Carmen (ed.), Mujeres, familias y linajes en la Edad Media, Granada, Universidad de Granada, pp. 105-136.

Zabalo, Javier (1973), La administración del reino de Navarra en el siglo XIV, Pamplona, Universidad de Navarra.

Fecha de recepción del artículo: agosto 2017

Fecha de aceptación y versión final: abril 2018 